\title{
PERAN ORANG TUA DALAM DETEKSI DAN INTERVENSI DINI TUMBUH KEMBANG PADA ANAK USIA BALITA DI RT 04 RW 01 DESA JAYARAGA KECAMATAN TAROGONG KIDUL - GARUT
}

\author{
Ema Arum Rukmasari ${ }^{1}$, Nina Sumarni ${ }^{2 *}$, Gusgus Graha $R^{3}$, Kosim $^{4}$ \\ Fakultas Keperawatan Universitas Padjadjaran Kampus Garut
}

Email Korespondensi: n.sumarni@unpad.ac.id

Disubmit: 19 September $2021 \quad$ Diterima: 17 Januari 2022 Diterbitkan: 01 Februari 2022

DOI: https://doi.org/10.33024/jkpm.v5i2.5512

\begin{abstract}
ABSTRAK
Periode usia balita merupakan "golden periode" masa yang relatif singkat dan tidak akan terulang kembali dalam kehidupan seorang anak. Sehingga para orang tua, pengasuh, dan pendidikp erlu memanfaatkan dengan sebaik-baiknya. Tumbuh kembang yang optimal adalah tercapainya proses tumbuh kembang yang sesuai dengan potensi yang dimiliki olehanak. Dengan mengetahui penyimpangan tumbuh kembang secara dini, maka dapatdilakukan berbagai upaya pencegahan, stimulasi dan penyembuhan serta pemulihannya sedini mungkin pada masa-masa proses tumbuh kembang anak. Kegiatan ini bertujuan untuk melibatkan orang tua agar mampu mengembangkan tumbuh kembang anak melalui stimulasi deteksi dan intervensi dini tumbuh kembang anak. Metode yang digunaan pada kegiatan ini ialah ceramah dan diskusi serta tanya jawab. Berdasarkan hasil kegiatan diketahui bahwa sebelum dilakukan Pendidikan kesehatan, sebagian besar orangtua belum memahami pentingnya stimulasi, deteksi dan Intervensi dini tumbuh kembang anak, dan setelah dilakukan pendidikan kesehatan, hampir 80 persen para peserta memahami pentingnya deteksidini tumbuh kembang anak. Saran bawalah anak ke Posyandu agar terpantau pertumbuhan dan perkembangannya.
\end{abstract}

Kata kunci: Peran orang tua, Deteksi dini, dan Intervensi

\begin{abstract}
The toddler age period is a relatively short "golden period" and will not be repeated in a child's life. So that parents, caregivers, and educators need to make the best use of it. Optimal growth and development is the achievement of a growth and development process that is in accordance with The potential possessed by the child. By knowing the deviations of growth and development early, various prevention, stimulation and healing efforts can be made as well as their recovery as early as possible during the period of the child's growth and development process child growth. The method used in this activity is lecture and discussion and question and answer. Based on the Result of the activity, it was found that before health education was conducted, most parents did not understand the importance of early detection, stimulation, and intervention for child development, and after health education was conducted, almost 80 percent of participants understood the importance of early detection of child
\end{abstract}


growth and development. Suggestion take the child to the Posyandu to monitor their growth and development.

Keywords: Role of parents, early detection, and intervention

\section{PENDAHULUAN}

Lima tahun pertama seorang anak (balita) merupakan masa pertumbuhan dan perkembangan otak manusia yang paling cepat juga sangat sensitif untuk menerima berbagai masukan dari lingkungan. Masa emas ini merupakan periode kritis proses tumbuh kembang anak karena pada masa ini kemampuan otak anak untuk menyerap segala bentuk informasi sangatlah tinggi karena sekitar $80 \%$ otak anak berkembang pada masa ini (Fristi et al., 2014).

Mengingat lima tahun pertama merupakan masa yang "relatif singkat" dan tidak akan terulang kembali dalam kehidupan anak, maka orang tua, pengasuh dan pendidik hendaknya memanfaatkan masa yang "pendek" ini, untuk mengoptimalkan nutrisi, kasih sayang serta stimulasi yang dibutuhkan oleh anakanaknya karena pada masa ini otak balita lebih peka terhadap asupan yang kurang mendukung pertumbuhan otaknya seperti asupan gizi yang tidak adekuat, kurang stimulasi dan kurang mendapatkan pelayanan kesehatan yang memadai (Izah et al., 2019).

Salah satu yang dapat dilakukan untuk memenuhi kebutuhan dan mengoptimalkan tumbuhnya otak balita ialah dengan memperhatikan segala proses tumbuh kembang anak. Tumbuh kembang optimal merupakan proses kontinyu yang terus berlangsung yang sesuai dengan potensi yang dimiliki oleh anak. Fase awal tumbuh kembang ini berlangsung pada rentang usia 0 - 5 tahun. Fenomena tumbuh kembang yang bersifat kuantitatif dan irreversible ini akan berpengaruh pada fase kehidupan selanjutnya sehingga orangtua harus lebih cermat dalam mengenali dan mencegah kelainan yang dialami sedini mungking sehingga anak mendapatkan hasil yang lebih optimal (Suzan \& Ayudia, 2020)

Berbagai upaya pencegahan, stimulasi serta pemulihan yang sedini mungkin pada masa-masa proses tumbuh kembang anak dapat dilakukan melalui proses pembinaan. Pembinaan tumbuh kembang anak secara komprehensif dan berkualitas dapat diselenggarakan melalui kegiatan stimulasi, deteksi dan intervensi dini penyimpangan tumbuh kembang balita (SDIDTK) dilakukan pada periode 5 (lima) tahun pertama kehidupan anak. (Izah et al., 2019). Deteksi dini melalui kegiatan SDIDTK sangat diperlukan untuk menemukan secara dini penyimpangan pertumbuhan, penyimpangan perkembangan, dan penyimpangan mental emosional pada anak sehingga dapat dilakukan intervensi dan stimulasi sedini mungkin untuk mencegah terjadinya penyimpangan pertumbuhan, penyimpangan perkembangan dan penyimpangan mental emosional yang menetap (Syofiah et al., 2020).

Kegiatan SDIDTK tidak hanya dilakukan pada anak yang dicurigai mempunyai masalah saja tetapi harus dilakukan pada semua balita dan anak prasekolah secara rutin yang dilakukan dua kali dalam setahun (Syofiah et al., 2020). Kegiatan ini merupakan upaya untuk membantu agar anak tumbuh dan berkembang secara optimal yaitu dengan cara deteksi adanya penyimpangan dan intervensi dini yang perlu dilaksanakan oleh semua pihak mulai dari tingkat keluarga, petugas kesehatan (mulai dari kader kesehatan sampai dokter spesialis), dan di semua tingkat pelayanan kesehatan mulai dari tingkat dasar sampai pelayanan yang lebih (Fazrin et al., 2018).

Peningkatan pengetahuan umum tentang kesehatan khususnya tumbuh 
kembang anak memerlukan proses pendidikan kesehatan yang berkesinambungan bagi orang tua dan berbagai lembaga pendidikan anak prasekolah.

\section{MASALAH}

Di Kabupaten Garut, deteksi pelayanan kesehatan untuk anak, terutama tumbuh kembang bayi, masih rendah. Berdasarkan Profil Kesehatan Kabupaten Garut tahun 2017, cakupan pelayanan untuk anak di bawah usia 5 tahun adalah 75,5\% (Dinkes Kabupaten Garut, 2017). Hal ini tentunya berdampak pada meningkatnya penyimpangan tumbuh kembang anak yang tidak disadari sejak dini. menemukan penyimpangan perkembangan dini pada bayi dan anak prasekolah dapat dilakukan dengan deteksi dini kelainan atau masalah tumbuh kembang anak akan memudahkan intervensi.

Desa Jayaraga adalah salah satu desa yang ada di kecamatan Tarogong kidul, dekat dengan Universitas Padjajaran. Desa Jayaraga sangat dekat dengan Universitas Padjadjaran dan merupakan salah satu desa di Kecamatan Tarogong kidul Kabupaten Garut, dengan banyak anak di bawah usia lima tahun. Di Rw 04 RT01, Unpad mendirikan Posyandu karena desa Jayaraga belum mendirikan Posyandu. Posyandu adalah salah satu bentuk pelayanan kesehatan. Diselenggarakan oleh masyarakat untuk masyarakat dibantu olehTenaga Kesehatan (Sugiyanto, Sumarlan, 2020)

Kegiatan yang dilakukan di posyandu ini meliputi kegiatan penimbangan balita dan pemberian nutrisi sehingga lebih terfokus pada pertumbuhan fisik sedangkan deteksi dini untuk mengetahui masalah perkembangan anak belum diberikan secara lengkap, sehingga diperlukan upaya pencegahan penyimpangan tumbuh kembang dengan melakukan deteksi dini di Posyandu (Sugeng et al., 2019).

Kader posyandu yang baru dibentuk pun belum mampu melakukan deteksi dini dan intervensi dini penyimpangan tumbuh kembang balita secara komprehensif. Pelayanan posyandu hanya terbatas pada deteksi dini penyimpangan pertumbuhan berdasarkan berat badan. Selain itu, masyarakat pun belum mampu melakukan stimulasi perkembangan anak sesuai usianya. leh karena itu, untuk dapat meningkatkan pengetahuan masyarakat tentang kesehatan, khususnya tentang tumbuh kembang pada anak, adalah dengan proses pendidikan kesehatan yang berkesinambungan.

Pengabdian Kepada Masyarakat (PKM) yang memiliki misi untuk ikut serta dalam pemecahan permasalahan di masyarakat, merupakan media yang sangat tepat untuk memfasilitasi masyarakat dalam meningkatkan kualitas kesehatannya. Sehingga perlu diadakannya pendidikan kesehatan tentang tumbuh kembang pada anak terutama tentang stimulasi, deteksi dini, intervensi dini tumbuh kembang pada anak. Berikut gambar peta lokasi kegiatan: 


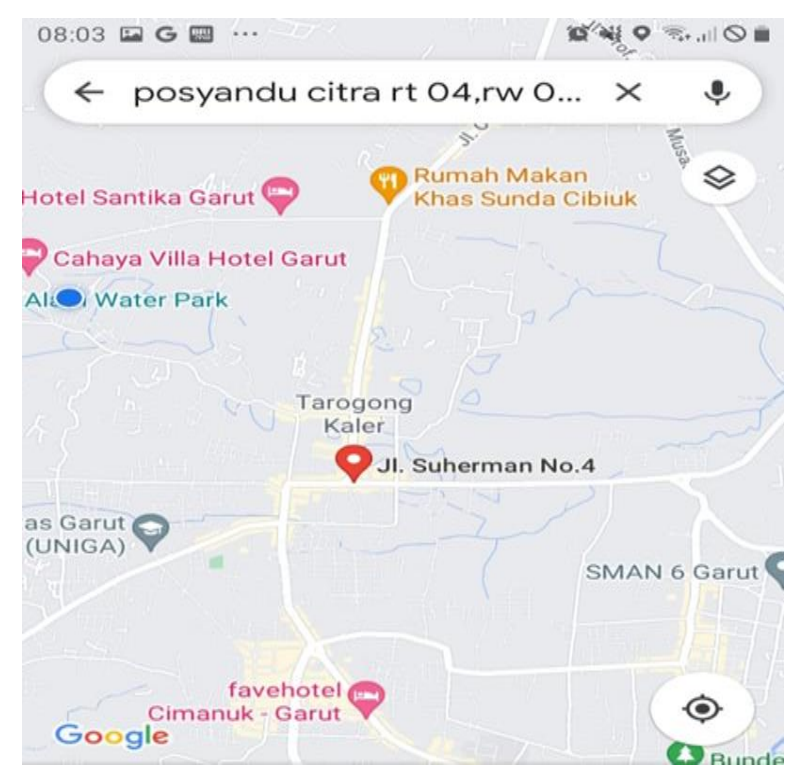

Gambar 1. Peta Lokasi Kegiatan

\section{METODE}

a. Tujuan Persiapan

Tahap persiapan dari kegiatan pengabdian masyarakat di wilayah Kerja Puskesmas Haurpanggung Garut yaitu di kampus Unpad garut Yaitu mempersiapakan alat bantu untuk kegiatan promo kesehatan, mulai dari pembuatan power poin dan leaflet.

b. Tahap pelaksanaan

Berdasarkan masalah di atas, maka realisasi pemecahanmasalah yang yang dilakukan adalah dengan memberikan Pendidikan Kesehatan tentang Stimulasi Deteksi dan Intervensi Dini Tumbuh Kembang (SDIDTK) pada ibu yang mempunyai anak usia balita. Khalayak sasaran pada kegiatan ini adalah kader dan orangtua anak usia balita di RT 04 RW 01 Desa Jayaraga Kecamatan Tarogong Kidul Kabupaten Garut sebanyak 21 orang.

c. Evaluasi

1) Struktur

Kegiatan pertama: yaitu Penyuluhan mengenai pentingnya stimulasi tumbuh kembang, deteksi dini tumbuh kembang, dan intervensi dini tumbuh kembang pada anak usia balita di RT 04 RW 01 Desa Jayaraga Kecamatan Tarogong Kidul Kabupaten Garut dengan alat bantu poster dan leaflet. Dalam penyampaian penyuluhan menggunakan bahasa daerah yang mudah dipahami oleh para peserta serta memberi kesempatan kepada peserta untuk bertanya atau diskusi selama proses penyuluhan berlangsung.

Kegiatan kedua : yaitu Simulasi pelaksanaan deteksi dini dan screening tumbuh kembang pada anakusia balita di RT 04 RW 01 Desa Jayaraga Kecamatan Tarogong Kidul Kabupaten Garut.

2) Proses

Pelaksanaan kegiatan penyuluhan dimulai pada pukul 10.30 setelah kegiatan pelayanan POSYANDU Citra di RT 04 RW 01 Desa Jayaraga Kecamatan Tarogong Kidul Kabupaten Garut merupakan daerah binaan Universitas Padjadjaran 


\section{HASIL DAN PEMBAHASAN}

Penyuluhan kesehatan dilaksanakan setelah kegiatan pelayanan Posyandu dimana dihadiri oleh ibu-ibu yang membawa anaknya ke pelayanan posyandu sebanyak 21 orang. Berdasarkan hasil pretes sebelumnya tentang tumbuh kembang skor rata rata adalah 50,60. Ini adalah hasil pengetahuan ibu ibu yang mempunyai balita tentang tumbuh kembang anak dengan skor minimal 50 dan maksimal 60.

Setelah dilakukan penyuluhan kesehatan tentang tumbuh kembang pada anak,kemudian dilakukan postes dengan skor rata rata 80 dengan skor minimal 70 dan skor maksimal 80. Pentingnya tumbuh kembang pada anak, Tumbuh kembang yang optimal adalah tercapainya proses tumbuh kembang yang sesuai dengan potensi yang dimiliki oleh anak.

Anak yg mempunyai awal tumbuh kembang yg baik akan tumbuh sebagai dewasa yg lebih sehat sebagai akibatnya akan mempunyai kehidupan yg lebih baik (D, 2016)

Dengan mengetahui penyimpangan tumbuh kembang secara dini, maka dapat dilakukan berbagai upaya pencegahan, stimulasi dan penyembuhan serta pemulihannya sedini mungkin pada masa-masa proses tumbuh kembang anak sehingga hasil yang diharapkan akan tercapai.
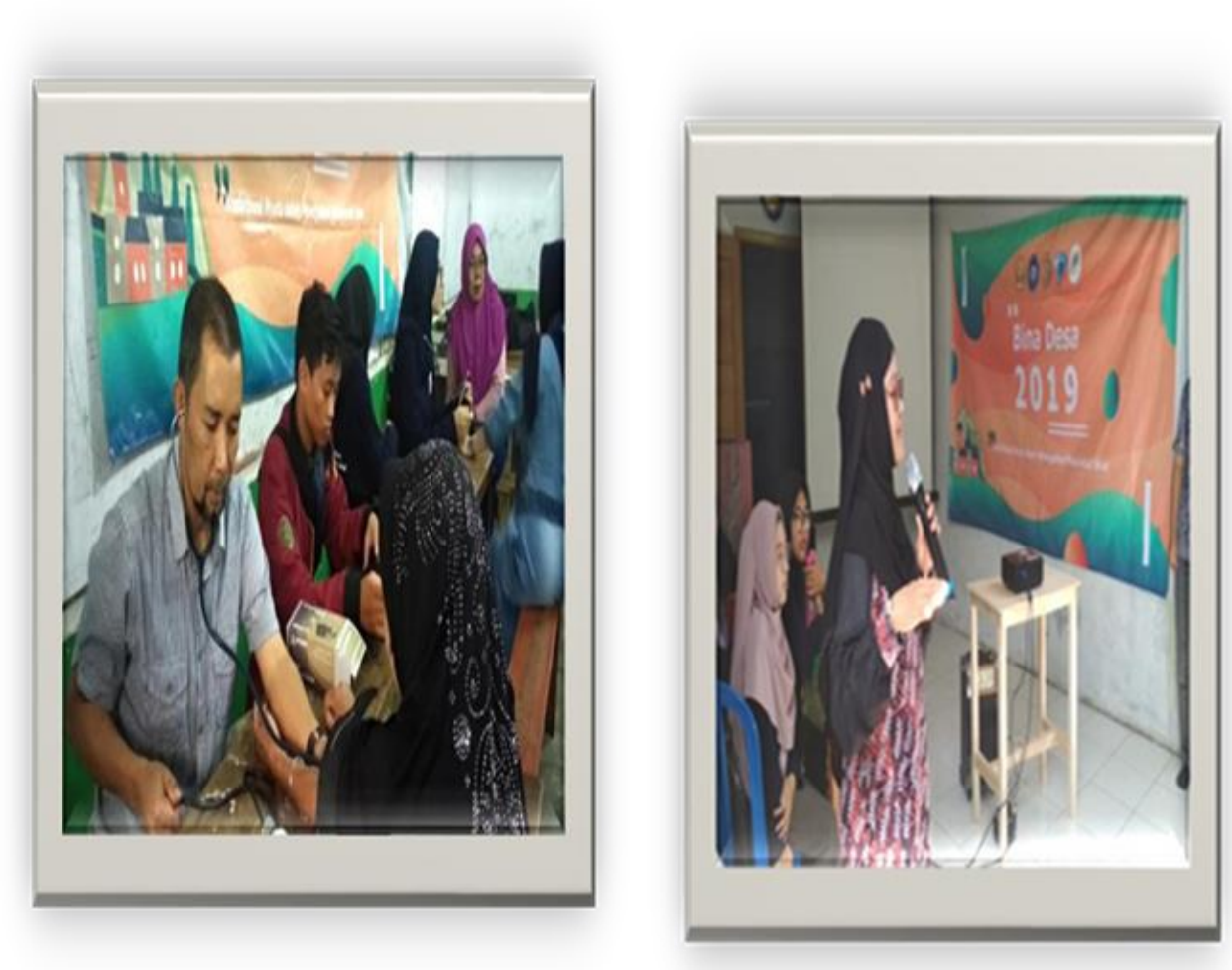

Gambar 4. Pelaksanaan Kegiatan Pengabdian Masyarakat 


\section{KESIMPULAN}

Kegiatan Pendidikan kesehatan dengan tema" Stimulasi Deteksi dan Intervensi Dini Tumbuh Kembang di Posyandu Citra RT 04 RW 12 Desa Jayaraga Kecamatan Tarogong Kidul Kabupaten Garut.Telah dilaksanakan dengan baik dan lancar.

Para Kader dan orangtua memahami tentang pentingnya Stimulasi Deteksi dan Intervensi Dini Tumbuh Kembang pada anak-anak balita, sehingga hal ini akan menjadi kegiatan rutin yang akan selalu dilaksanakan di posyandu tersebut.

Teridentifikasinya jumlah penemuan penyimpangan (case finding) tumbuh kembang pada anak usia balita di RT 04 RW 12 Desa Jayaraga Kecamatan Tarogong Kidul Kabupaten Garut.

\section{DAFTAR PUSTAKA}

D, P. (2016). Factors Affecting Early Childhood Growth and Development: Golden 1000 Days. Advanced Practices in Nursing, 01(01), 1-4. https: / /doi.org/10.4172/2573-0347.1000101

Dinkes Kabupaten Garut. (2017). Profil Kesehatan Kab. Garut Tahun 2017. Fazrin, I., Widiana, D., Trianti, I. R., Baba, K. J., Amalia, N. M., \& Smaut, M. Y. (2018). Pendidikan Kesehatan Deteksi Dini Tumbuh Kembang pada Anak di Paud Lab School UNPGRI Kediri Journal of Community Engagement in Health. Journal of Community Engagement in Health, 1(2), 6-14. https: //doi.org/10.30994/jceh.v1i2.8

Fristi, W., Indriati, G., \& Erwin. (2014). Perbandingan Tumbuh Kembang Anak Toddler yang Diasuh Orang Tua dengan Diasuh Selain Orang Tua. Jurnal Online Mahasiswa Program Studi Ilmu Keperawatan Universitas Riau, 1(2), 1-8.

Izah, N., Prastiwi, R. S., \& Andari, I. D. A. (2019). Stimulasi Dan Deteksi Dini Tumbuh Menggunakan Aplikasi Tumbuh Kembang Balita di Wilayah Kelurahan MArgadana. Jurnal Abdimas PHB, 2(2), 21-28.1

Sugeng, H. M., Tarigan, R., \& Sari, N. M. (2019). Gambaran Tumbuh Kembang Anak pada Periode Emas Usia 0-24 Bulan di Posyandu Wilayah Kecamatan Jatinangor. Jsk, 4(3), 96-101.

Sugiyanto, Sumarlan, A. J. H. (2020). Analysis of Balanced Nutrition Program Implementation Against Stunting in Toddlers. Unnes Journal of Public Health, 9(2), 1-10.

Suzan, R., \& Ayudia, E. I. (2020). Pemeriksaan pertumbuhan dan perkembangan anak dengan kpsp di paud islam an nur kota jambi. Jurnal Pengabdian Masyarakat, 3, 95-98.

Syofiah, P. N., Machmud, R., \& Yantri, E. (2020). Analisis Pelaksanaan Program Stimulasi, Deteksi dan Intervensi Dini Tumbuh Kembang (SDIDTK) Balita di Puskesmas Kota Padang Tahun 2018. Jurnal Kesehatan Andalas, 8(4), 151156. https: //doi.org/10.25077/jka.v8i4.1133 